Мальцев Д.В.

Институт экспериментальной и клинической медицины Национального медицинского университета имени А.А. Богомольца, Киев, Украина

Maltsev D.

Institute of Experimental and Clinical Medicine at the O'Bogomolets NMU, Kyiv, Ukraine

\title{
Эффективность ритуксимаба
} при расстройствах спектра аутизма, ассоциированных с генетическим дефицитом фолатного цикла, с признаками антинейронального аутоиммунитета*

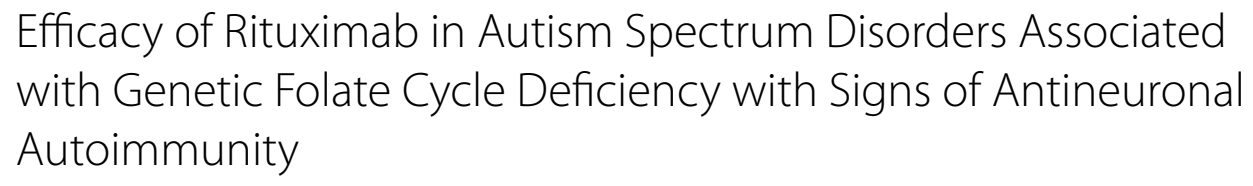

Введение. Установлена ассоциация генетического дефицита фолатного цикла (ГДФЦ) и РАС, в таких случаях антинейрональный аутоиммунитет (АА) является механизмом поражения ЦНС. Цель исследования: изучить эффективность ритуксимаба у детей с РАС, ассоциированными с ГДФЦ, с серологическими признаками АА для расширения арсенала нейропротекторной терапии.

Материалы и методы. Проанализированы данные 138 детей с ГДФЦ и РАС (97 мальчиков и 41 девочка). 62 из 81 пациента с признаками АА проходили иммунотерапию ритуксимабом в дозе 375 мг/м²/мес 3-9 мес. (исследуемая группа, ИГ). Родственники 19 пациентов отказались от лечения (контрольная группа, КГ). Динамику психического состояния оценивали по шкале АВС. Рассчитывали Т-критерий Стьюдента с показателем р и число знаков Z по Урбаху, а также - OR и 95\% Cl.

Результаты и обсуждение. Достигнуто прогрессивное снижение сывороточной концентрации антинейрональных аутоАТ с более выраженным эффектом при АТ к калиевым каналам нейронов по сравнению с AT к GADA ( $p<0,05: Z<Z_{0,05}$ ) с устранением аутоAT после 3-9-месячного курса в $92 \%$ случаев ( $<<0,05: Z<Z_{0,05}$ ). Это было ассоциировано с эффектом нейропротекции за счет нормализации сывороточных концентраций NSE (OR 17,875; 95\% Cl 4,738-67,436 при AT к GADA; 41,800; 7,257-240,778 при AT к калиевым каналам) и белка S-100 (9,750; 2,707-35,113 и 18,333; 3,462-97,083 соответственно). Отмечалось прогрессивное улучшение показателей шкалы $A B C$ с латентным периодом около 2 месяцев ( $\left.<<0,05: Z<Z_{0,05}\right)$.

Выводы. Ритуксимаб, устраняя серологические признаки $A A$, вероятно, реализует эффект нейропротекции, уменьшая тяжесть РАС у детей с ГДФЦ. Необходимы дальнейшие исследования для уточнения полученных данных.

Ключевые слова: гиперактивность, гипервозбудимость, аутоиммунный энцефалит.

* На правах рекламы. 


\section{Abstract}

Backgrounds. The association of genetic deficiency of the folate cycle (HDFC) and ASD has been established; in such cases, antineuronal autoimmunity (AA) is the mechanism for the formation of brain damage.

The aim: to study the efficacy of rituximab in children with ASD associated with HDFC, with serological signs of AA for expanding the arsenal of neuroprotective therapy.

Materials and methods. The data of 138 children with HDFC and ASD ( 97 boys and 41 girls) were analyzed. 62 of 81 patients with signs of AA underwent immunotherapy with rituximab at a dose of $375 \mathrm{mg} / \mathrm{m}^{2} / \mathrm{month}$ for 3-9 months (study group, SG). Relatives of 19 patients refused treatment (control group, CG). The dynamics of the mental state was assessed using the $A B C$ scale. The Student's $t$-test was calculated with the $p$ index and the number of signs $Z$ by Urbach, as well as OR and $95 \% \mathrm{Cl}$.

Results and discussion. A progressive decrease in the serum concentration of antineuronal autoAb was achieved with a more pronounced effect with AT to the potassium channels of neurons compared with AT to GADA ( $p<0.05: Z<Z_{0.05}$ ) with the elimination of autoAb after a 3-9-month course in $92 \%$ of cases $\left(p<0.05: Z<Z_{0.05}\right.$ ). This was associated with the effect of neuroprotection due to the normalization of serum concentrations of NSE (OR 17.875; $95 \% \mathrm{Cl} 4.738-67.436$ with $\mathrm{Ab}$ to GADA; $41.800 ; 7.257-240.778$ with Ab to potassium channels) and S-100 protein (9.750; $2.707-$ 35,113 and 18,$333 ; 3,462-97,083$ respectively). There was a progressive improvement in the $A B C$ scale indicators with a latency period of about 2 months $\left(p<0.05: Z<Z_{0.05}\right)$.

Conclusions. Rituximab, eliminating serological signs of $\mathrm{Al}$, probably, realizes the effect of neuroprotection, reducing the severity of ASD in children with HDFC. Further research is needed to clarify the data obtained.

Keywords: hyperactivity, hyperexcitability, autoimmune encephalitis.

\section{- ВВЕДЕНИЕ}

За счет открытий в генетике, молекулярной биологии и иммунологии, которые произошли за последние десятилетия, в значительной степени изменились взгляды на этиологию и патогенез расстройств спектра аутизма (РАC) у детей. Одним из ключевых достижений в этом направлении является установление ассоциации генетического дефицита фолатного цикла (ГДФЦ) и РАС, доказательства которой основываются на результатах 5 метаанализов рандомизированных контролируемых клинических исследований и ряда дополнительных контролируемых испытаний [1-5].

Как известно, цикл фолиевой кислоты реализуется благодаря деятельности трех ключевых ферментов: метилентетрагидрофолатредуктазы (MTHFR), метионинсинтазы-редуктазы (MTRR) и метионинсинтазы (MTR). Этот цикл функционирует в неразрывной связи с циклом метионина, в результате нарушения работы которого синтезируется токсичный продукт, получивший название гомоцистеин. На данный момент описаны две основные патогенные полиморфные замены нуклеотидов в гене MTHFR, связанные с заменой цитозина на тимин в кодоне 677 (MTHFR 677 C>T; rs1801133) и аденина на цитозин в кодоне 1298 (MTHFR 1298 A >C; rs1801131), с которыми ассоциировано развитие PAC у детей. B генах MTRR и MTR известны второстепенные патогенные 
полиморфизмы, обусловленные заменой аденина на гуанозин (A>G) в кодонах 66 (MTRR A66G) и 2756 (MTR A2756G), отягощающие биохимические нарушения, вызванные MTHFR C677T и MTHFR A1298C [4, 5].

Установлено, что ГДФЦ приводит к патологическим биохимическим изменениям в организме ребенка, которые обуславливают развитие энцефалопатии с клинической картиной РАС за счет прямого (метаболического) и непрямого (иммуноопосредованного) механизмов, причем иммунозависимым путям церебрального повреждения отводят ведущую роль в патогенезе данного психического расстройства. Среди индуцированных ГДФЦ нарушений обмена веществ в организме ребенка выделяют гипергомоцистеинемию, дефицит ряда витаминов, признаки митохондриальной дисфункции, нарушение синтеза нуклеотидов и процессов метилирования ДНК, белков и липидов [6-8]. Эти патологические биохимические изменения обусловливают развитие персистирующего оксидативного стресса, доказательством которого являются результаты двух систематических обзоров и метаанализов рандомизированных контролируемых клинических исследований по этой проблеме $[9,10]$. Следствием таких нарушений являются феномены нейро- и иммунотоксичности, лежащие в основе указанных выше прямых и непрямых механизмов нейронального повреждения у детей с РАС. Если говорить об иммунотоксичности, то сейчас установлено, что при ГДФЦ отмечается нарушенное развитие иммунной системы ребенка с формированием иммунной дисфункции и дизрегуляции, которые в свою очередь обуславливают феномен, получивший название нарушенного нейроиммунного интерфейса $[11,12]$. Наличие иммунной дисфункции при ГДФЦ предрасполагает к развитию иммунозависимых осложнений. Известно не менее трех независимых иммуноопосредованных механизмов поражения ЦНС при ГДФЦ, обусловленных персистирующей иммунной дисфункцией, которые осуществляют вклад в формирование энцефалопатии с клинической картиной РАС. Речь идет о развитии нейротропных оппортунистических и условно патогенных инфекций [13], аутоиммунных реакций к нейронам и миелину полушарий большого мозга [14, 15], системного и связанного с этим интрацеребрального асептического воспаления, вызванного иммунной дизрегуляцией [16, 17]. Поэтому говорят именно об иммунозависимой энцефалопатии у детей с РАС, ассоциированными с ГДФЦ. Патогенез этой энцефалопатии несколько отличается у разных пациентов, поскольку у одних преобладает инфекционный фактор, как указывают сообщения о развитии аутистического регресса после височного энцефалита, вызванного вирусом простого герпеса 1-го типа [18, 19], у других же - аутоиммунные и иммуновоспалительные механизмы поражения ЦНС, о чем свидетельствуют публикации о появлении симптомов РАС у детей с аутоиммунными лимбическими энцефалитами [20, 21].

Особую роль в патогенезе энцефалопатии у детей с РАС отводят аутоиммунным механизмам. Такие представления основываются на ряде доказательств. Во-первых, результаты ряда контролируемых клинических исследований указывают на аномальное обнаружение у пациентов с РАС аутоантител к нейронам ЦНС, валидированных ранее как маркеры аутоиммунных энцефалитов, которые не отмечаются у здоровых детей. Tак, Rout U.K. с соавт. обнаружили аутоантитела к мозговому антигену 
GAD65 (GADA) среди детей с аутизмом в 15\% случаев, аутистическим спектром - в 27\% случаев и ни у одного здорового ребенка группы контроля [22]. Эти аутоантитела являются признанным лабораторных маркером так называемого аутоиммунного анти-GAD65 лимбического энцефалита, приводящего к развитию ряда тяжелых нарушений психики у детей и взрослых. В то же время Frye R.E. с соавт. идентифицировали антитела к рецепторам фолиевой кислоты нейронов головного мозга у детей с РАС, что указывает на гетерогенность проявлений антимозгового аутоиммунитета в таких случаях [23]. Cabanlit M. с соавт. установили ассоциацию РАС и наличия аутоантител к нейронам гипоталамуса и таламуса [24]. Во-вторых, существует ряд описаний острого развития клинических проявлений РАС после начала верифицированного аутоиммунного лимбического энцефалита у детей и достижения клинического улучшения в результате лечения аутоиммунной болезни. Tак, GonzálezToro M.C. с соавт. сообщили о двух случаях аутоиммунного анти-NMDA лимбического энцефалита у детей, клинические проявления которых соответствовали симптомам PAC [20]. Kiani R. с соавт. также доложили об аутистическом регрессе при развитии аутоиммунного анти-NMDA лимбического энцефалита у ребенка [21]. В-третьих, при РАС продемонстрировали клиническую эффективность несколько препаратов с противовоспалительным и иммуномодулирующим действием, механизм влияния которых связывают именно с подавлением антинейронального аутоиммунитета и связанного с этим интрацеребрального воспаления. В частности, в сообщениях о клинических случаях и результатах небольших испытаний показана польза от применения глюкокортикостероидов и других противовоспалительных агентов у детей с РАС, механизм действия которых усматривают именно в реализации противовоспалительного действия и угнетении антимозгового аутоиммунитета [18]. Проведено не менее 10 клинических исследований по испытанию иммуномодулирующего агента в/в нормального иммуноглобулина человека при РАС, который, как полагают, улучшает психические функции пациентов благодаря подавлению интрацеребрального воспаления и аутоиммунных реакций против мозговых аутоантигенов [19-28]. Недавно противовоспалительный агент инфликсимаб, препарат моноклональных антител против молекулы фактора некроза опухоли альфа, продемонстрировал эффективность по подавлению проявлений гиперактивности и гипервозбудимости у детей с РАС, ассоциированных с ГДФЦ, в контролируемом клиническом исследовании [29].

Подавление или устранение иммунозависимых механизмов повреждения ЦНС представляется перспективной стратегией лечения РАС у детей с ГДФЦ. В частности, считают, что угнетение аутоиммунитета к нейронам и миелину может существенно улучшить психические функции больных детей. Хотя в этом направлении уже проведен ряд клинических исследований, доказательная база иммуномодулирующей терапии при РАС, ассоциированных с ГДФЦ, все еще остается недостаточной, что обусловливает необходимость проведения дальнейших научных работ в указанной области.

Перспектива разработки новых, более эффективных и безопасных методов лечения иммуноопосредованной энцефалопатии у детей с РАС является важной задачей современной нейроиммунологии. Учитывая, 
что аутоиммунные реакции к аутоантигенам ЦНС при РАС, как полагают, реализуются преимущественно за счет аутоантител, а не клеточной аутоиммунной реакции, перспективным для применения у таких детей представляется препарат моноклональных антител к молекуле CD20 В-лимфоцитов ритуксимаб, который уже прошел ряд успешных испытаний при аутоиммунных болезнях с аналогичным механизмом развития [30]. Теоретически за счет индукции В-клеточной деплеции ритуксимаб может существенно подавить или даже устранить продукцию аутоантител к мозговым аутоантигенам у детей с РАС, оказывая нейропротекторный эффект и улучшая тем самым психический статус пациентов. Необходимо проведение специального клинического исследования по апробации ритуксимаба у детей с РАС, ассоциированными с ГДФЦ, с признаками антимозгового гуморального аутоиммунитета.

\section{- ЦЕЛЬ ИССЛЕДОВАНИЯ}

Изучить эффективность применения ритуксимаба у детей с РАС, ассоциированными с ГДФЦ, у которых отмечаются серологические признаки антинейронального аутоиммунитета для расширения современного арсенала нейропротекторной терапии при иммуноопосредованной энцефалопатии в таких случаях.

\section{- МАТЕРИАЛЫ И МЕТОДЫ}

Проанализированы медицинские данные 138 детей в возрасте от 3 до 8 лет с ГДФЦ, у которых отмечались клинические проявления РАС (97 мальчиков и 41 девочка). Все они были пациентами специализированной нейроиммунологической клиники Vivere (регистрационное досье от 22.12.2018 № 10/2212-М). Получение данных для исследования и обработка материала проводились согласно договору № 150221 от 15.02.2021 г. и заключению комиссии биоэтической экспертизы (протокол № 140 от 21.12.2020 г. НМУ имени А.А. Богомольца). Диагноз расстройств спектра аутизма был выставлен детскими психиатрами по критериям DSM-IV-TR (Diagnostic and Statistical Manual of mental disorders) и ICD-10 (The International Statistical Classification of Diseases and Related Health Problems). Патогенные полиморфные варианты генов ферментов фолатного цикла определяли методом ПЦР с рестрикцией на основании выявления замены нуклеотидов MTHFR C677T в моноформе (27 пациентов), а также в сочетании с другими заменами нуклеотидов - MTHFR A1298C, MTRR A66G и/или MTR A2756G (111 человек) (Синево, Украина).

Исключали наличие инфекционного фактора за счет поиска HSV1/2, VZV, EBV, CMV, HHV-6, HHV-7, HHV-8, TTV, Mycoplasma pneumoniae, Chlamydia pneumoniae, Borrelia bugdorferi, Candida albicans, Cryptoccocus neoformans, Toxoplasma gondii, Streptococcus pyogenes (ПЦР, специфические IgM, IgA, IgG; отдел нейробиохимии Института нейрохирургии НАМН Украины).

Оценивали результаты серологических исследований сыворотки крови на предмет выявления специфических антинейрональных аутоантител, валидированных ранее как маркеры аутоиммунных лимбических энцефалитов у детей и взрослых, а именно - аутоантител к глутаминокислой декарбоксилазе (GADA), калиевым каналам нейронов, амфифизину, NMDA-рецепторам нейронов, GABA, CV2, Yo, Ro, Hu, AMPAR 1 и 2 
(ELISA; MDI Limbach Berlin GmbH, Германия). Положительные результаты таких лабораторных исследований выявлены у 81 пациента.

Эти результаты сочетались с признаками гиперинтенсивности МРсигнала от структур мезолимбической системы височных долей полушарий большого мозга (гиппокампов, островков, парагиппокампальных извилин, миндалевидных тел) в режимах T2 и FLAIR при проведении МР-нейровизуализации на МР-томографах с величиной магнитной индукции катушки не менее 1,5 Тл (рис. 1), а также - с ЭЭГ-картиной височной медианной эпилепсии при осуществлении нейрофункциональных исследований (рис. 2). Таким образом, у этих лиц имели место лабораторно-инструментальные признаки, описанные ранее и валидированные как проявления аутоиммунного лимбического энцефалита. С выявленной хронической антинейрональной аутоиммунной реакцией можно было связать по крайней мере часть имеющихся клинических проявлений нейропсихиатрических расстройств у детей. Этим пациентам было предложено лечение ритуксимабом согласно данным последнего систематического обзора и метаанализа рандомизированных контролируемых клинических исследований по проблеме терапии аутоиммунных лимбических энцефалитов у людей [37].

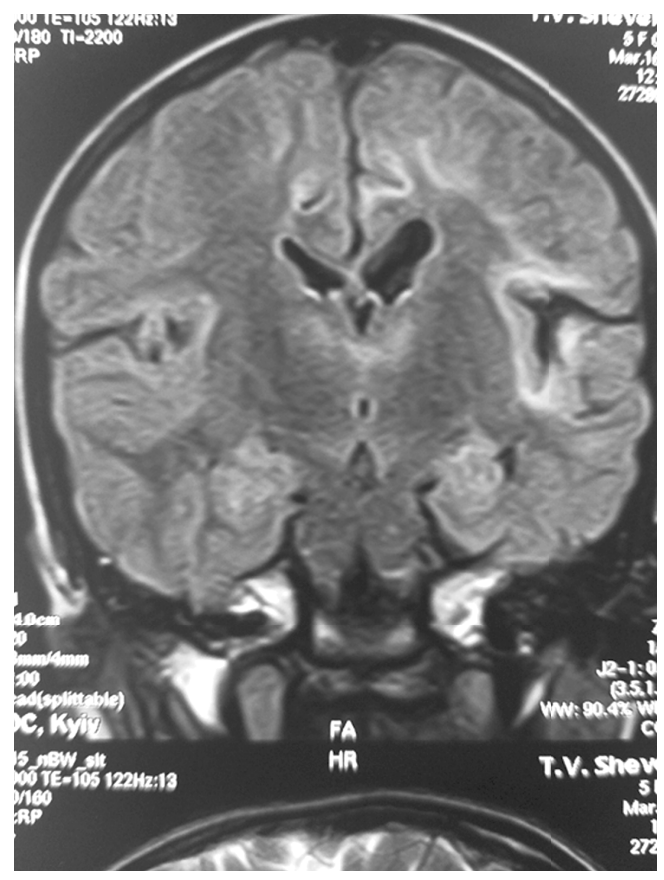

Рис. 1. МР-картина билатерального аутоиммунного лимбического энцефалита с асимметричным поражением гиппокампов и островков, ассоциированного с продукцией аутоантител к калиевым каналам нейронов, у ребенка с PAC, ассоциированными с ГДФЦ (режим FLAIR, коронарная проекция; собственное наблюдение)

Fig. 1. MR picture of bilateral autoimmune limbic encephalitis with asymmetric lesions of the hippocampus and insulas associated with the production of autoantibodies to potassium channels of neurons in a child with ASD associated with HDFC (FLAIR mode, coronary projection; own observation) 


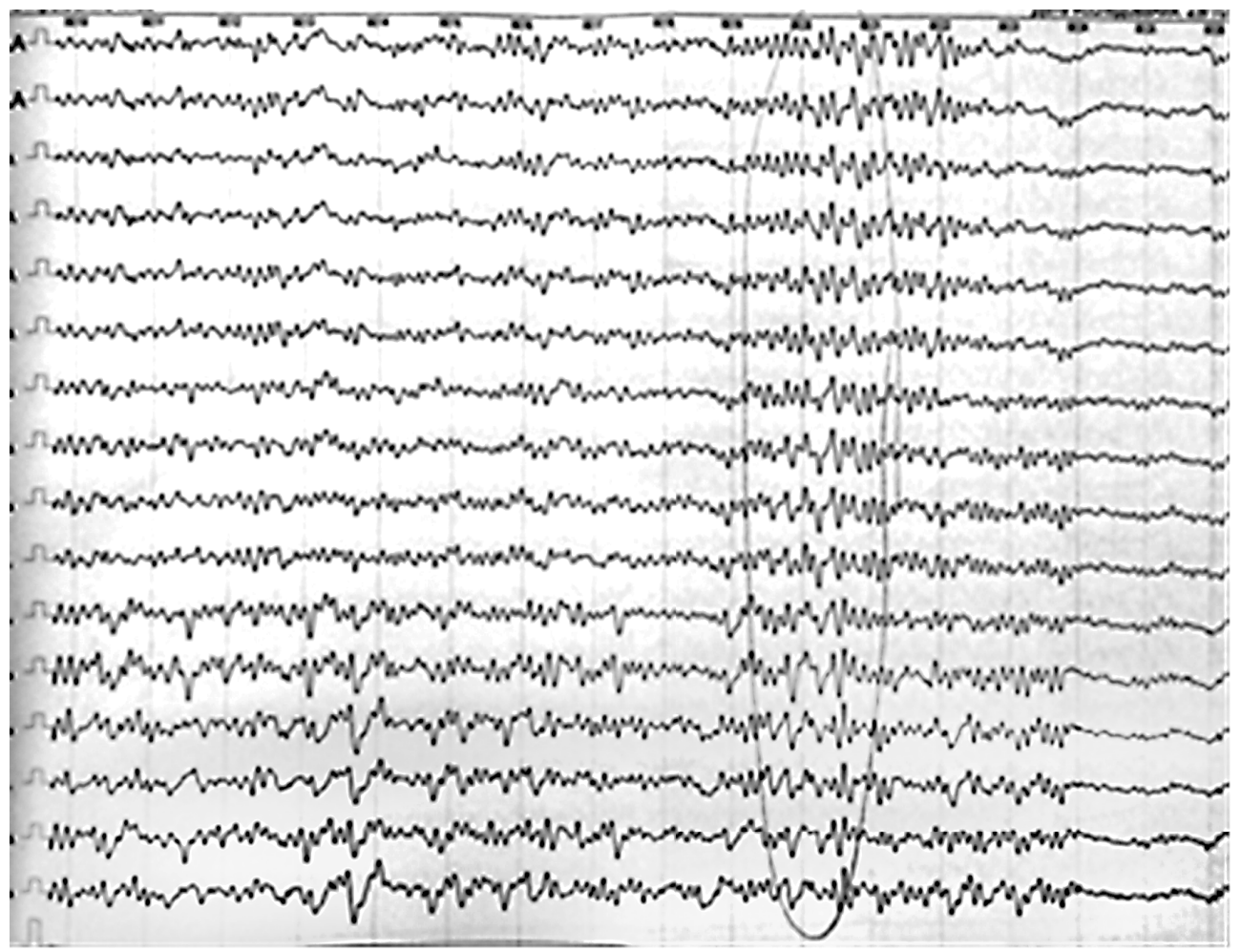

Рис. 2. ЭЭГ-картина эпилептиформной биоэлектрической активности, ассоциированной с индуцированным аутоантителами к GADA височным медианным склерозом, у ребенка с PAC, связанными с ГДФЦ (патологические волны обведены; собственное наблюдение)

Fig. 2. EEG picture of epileptiform bioelectric activity associated with induced by autoantibodies to GADA temporal mesial sclerosis in a child with ASD associated with HDFC (pathological waves are circled; own observation)

Родители 62 из 81 пациента с РАС с признаками антинейронального аутоиммунитета согласились на предложенную иммунотерапию. Их дети составили исследуемую группу (ИГ). Аутоантитела к GADA имели место в ИГ у 30 пациентов (48\%), к калиевым каналам нейронов - у 24 человек (39\% случаев). Также изредка встречались аутоантитела к амфифизину (3 человека, 5\%), NMDA-рецепторам нейронов (3 человека, 5\%) и молекуле CV2 (2 человека, 3\% случаев) (рис. 3). Родственники других 19 пациентов с подобным распределением по характеру антинейрональных аутоантител отказались от такого лечения (контрольная группа, КГ).

Поскольку сывороточные концентрации различных антинейрональных аутоантител измерялись в различных единицах, для проведения обобщенного анализа данных использовали специальную балльную оценку. Превышение концентрации в сыворотке крови определенного аутоантитела до 20\% от верхней границы референтных величин оценивали как 1 балл, от 21 до 40\% - 2 балла, от 41 до 60\% - 3 балла, от 61 до 


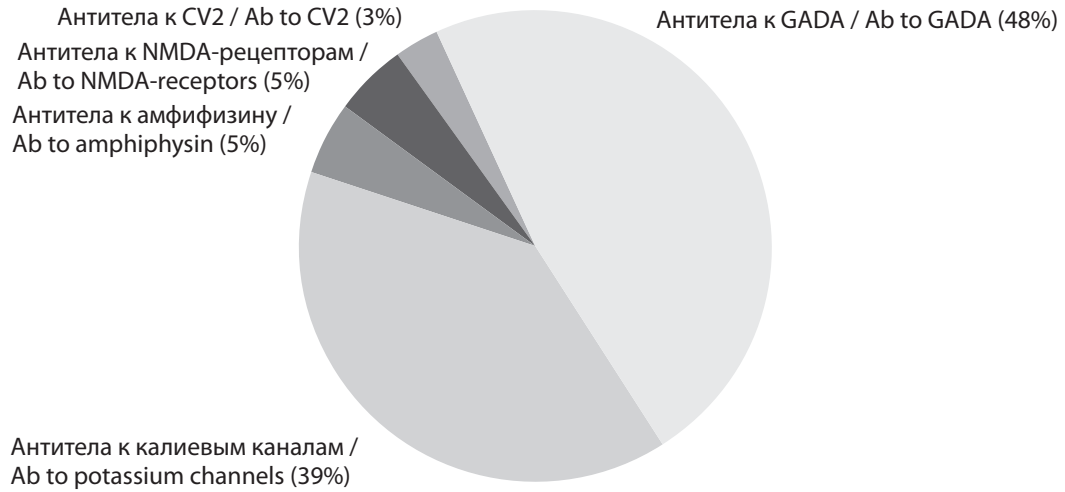

Рис. 3. Структура ИГ (n=62) по типу сывороточных аутоантител к аутоантигенам нейронов ЦНС

Fig. 3. Structure of SG $(n=62)$ by the type of serum autoantibodies to autoantigens of CNS neurons

$80 \%$ - 4 балла, а более $81 \%$ - 5 баллов. Поскольку аутоантитела к GADA и калиевым каналам нейронов встречались у многих пациентов, провели отдельный анализ данных по этим показателям, однако подобный анализ не удалось осуществить по аутоантителам к NMDA-рецепторам нейронов, амфифизину и CV2 из-за малого количества случаев их идентификации среди обследованных пациентов.

Ритуксимаб, препарат моноклональных антител к молекуле CD20 В-лимфоцитов, вводили в/в капельно в дозе $375 \mathrm{mr} / \mathrm{M}^{2}$ поверхности кожи ребенка с частотой 1 раз в 1 месяц под контролем результатов определения сывороточных концентраций аутоантител к аутоантигенам нейронов мезолимбической системы головного мозга до момента исчезновения таких аутоантител из сыворотки крови ребенка. Всего проводили от 3 до 9 курсов иммунотерапии ритуксимабом у детей ИГ.

Оценивали динамику клинических симптомов РАС согласно специализированной шкале Aberrant Behavior Checklist (ABC) у детей ИГ и КГ для того, чтобы определить, насколько уменьшение сывороточной концентрации антинейрональных аутоантител влияет на показатели клинического статуса пациентов.

Статистическую обработку материала проводили путем сравнительного и структурного анализов. Для определения достоверности различий между исследуемыми показателями в группах наблюдения использовали параметрический Т-критерий Стьюдента с показателем доверительной вероятности р и непараметрический критерий - число знаков Z по Урбаху Ю.В. Для исследования ассоциации динамики сывороточных концентраций антинейрональных аутоантител и индикаторов церебрального повреждения у детей с РАС проводили расчет показателя отношения шансов (OR) и 95\% доверительного интервала $(95 \% \mathrm{Cl})$.

Для проведения статистических расчетов пользовались программой Microsoft Excel.

Исследование выполнялось как фрагмент научно-исследовательской работы по заказу МЗ Украины (№ госрегистрации 0121U107940). 


\section{- РЕЗУЛЬТАТЫ И ОБСУЖДЕНИЕ}

Данные структурного и сравнительного анализов результатов применения апробированной иммунотерапии среди пациентов групп наблюдения указывают, что нормализация ранее повышенной концентрации в сыворотке крови антинейрональных аутоантител у детей ИГ после 3-месячного курса иммунотерапии ритуксимабом отмечалась в 37\% случаев, после 6-месячного - в 79\% случаев, а после 9-месячного в 92\% случаев, в то время как в КГ аналогичные показатели соответствовали уровням 7, 11 и 14\% случаев, что составило достоверное отличие от ИГ ( $\left.p<0,05 ; Z<Z_{0,05}\right)$ (рис. 4). Средний курс иммунотерапии ритуксима-

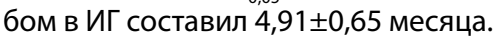

Хотя отмечался небольшой удельный вес спонтанных нормализаций сывороточных концентраций антинейрональных аутоантител в КГ, иммунотерапия ритуксимабом ассоциировалась с 5-кратным увеличением количества случаев получения нормального уровня сывороточной концентрации указанных аутоантител уже после 3 месяцев иммунотерапии, 11-кратным - после 6 месяцев иммунотерапии, и более чем 14-кратным - после 9 месяцев применения апробированного препарата моноклональных антител. Таким образом, использование ритуксимаба может быть ассоциировано с прогрессивным увеличением случаев негативизации ранее положительных результатов измерения концентрации антинейрональных аутоантител в сыворотке крови детей ИГ по мере продолжения курса иммунотерапии. Только 8\% детей ИГ обнаружили устойчивость к 9-месячному курсу ритуксимаба. Дополнительный анализ показал, что все эти дети имели балльную оценку антинейрональной аутоиммунной реакции к моменту начала иммунотерапии на максимальном уровне (5 баллов), что указывало на большую интенсивность аутоиммунной реакции. У всех этих детей имело место снижение сывороточной концентрации антинейрональных антител на момент 9-го месяца иммунотерапии как минимум на 60\%, что, по-видимому, указывало на частичную, а не тотальную резистентность к проведенным иммунотерапевтическим вмешательствам.

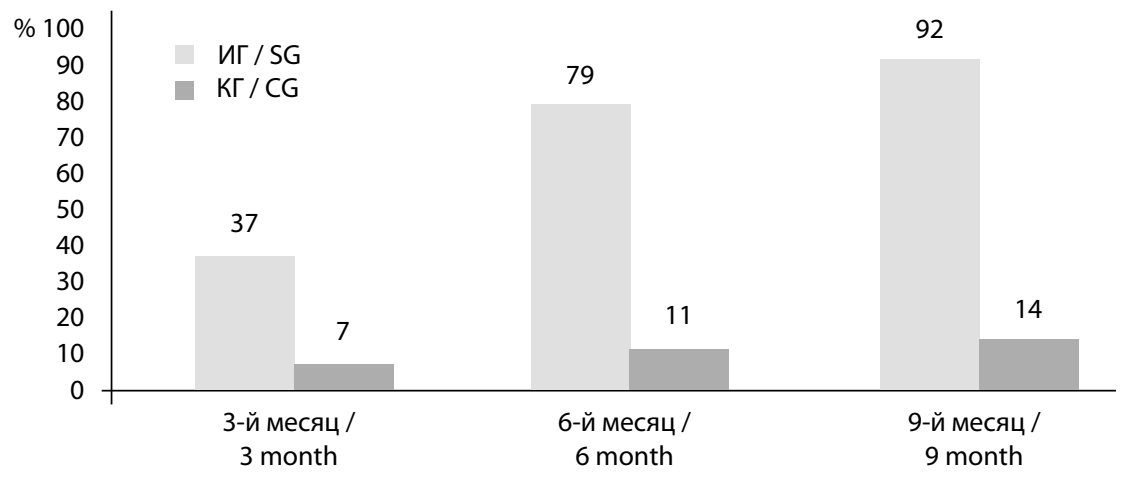

Рис. 4. Сравнение удельного веса случаев устранения сывороточных антинейрональных аутоантител у пациентов ИГ ( $\mathrm{n}=62)$ и КГ $(\mathrm{n}=19)$ в течение курса иммунотерапии ритуксимабом

Fig. 4. Comparison of the proportion of cases of elimination of serum antineuronal autoantibodies in patients SG ( $n=62)$ and CG ( $n=19$ ) during the course of immunotherapy with rituximab 
Результаты исследования ежемесячной динамики балльной оценки интенсивности антинейрональной аутоиммунной реакции указывают, что в течение всего курса ритуксимаба отмечалось прогрессивное уменьшение сывороточной концентрации антинейрональных аутоантител у детей ИГ. Так, средний балл оценки антинейрональной аутоиммунной реакции в ИГ к моменту начала иммунотерапии составлял 4,32 $\pm 0,27$ балла, тогда как после 9-месячного курса терапии - всего 1,31 0,14 балла, что свидетельствовало о снижении интенсивности совокупной аутоиммунной реакции почти в 4 раза, хотя в КГ не отмечалось существенной динамики балльной оценки аутоиммунитета против

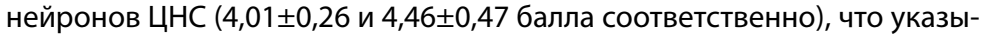
вало на достоверные отличия между результатами групп наблюдения $\left(\mathrm{p}<0,05 ; \mathrm{Z}<\mathrm{Z}_{0,05}\right)$ (рис. 5).

Отмечалась задержка в серологическом ответе на иммунотерапию ритуксимабом как минимум на 2 месяца от начала иммунотерапии, что можно объяснить периодом полного распада предсуществующих аутоантител к нейронам, синтезированных В-лимфоцитами до старта иммунотерапевтических вмешательств, который составляет около 42-46 суток [37].

Эти данные позволяют считать, что ритуксимаб может влиять на выраженность аутоиммунной реакции против нейронов ЦНС у детей с РАС, ассоциированными с ГДФЦ. Вероятнее всего, положительный эффект иммунотерапии развивается быстро, уже в течение первых 3 месяцев иммунотерапии, постепенно нарастает по мере продолжения курса иммунотерапии и приводит к устранению признаков аутоиммунитета почти во всех случаях.

Скорость достижения конечной точки - устранение антинейрональных аутоантител из сыворотки крови пациентов - по-видимому, зависит от исходного уровня их концентрации в сыворотке крови, поскольку 89\% пациентов ИГ, у которых отмечалось исчезновение серологических признаков аутоиммунитета уже после первых 3 месяцев иммунотерапии, имели низкую исходную балльную оценку аутоиммунной

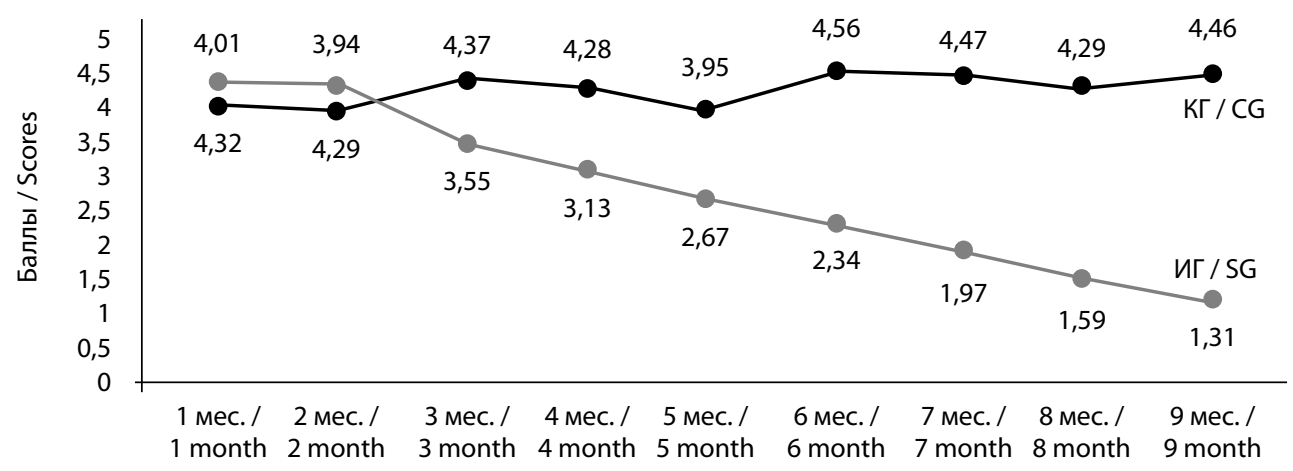

Рис. 5. Динамика сывороточных концентраций антинейрональных аутоантител у пациентов ИГ ( $\mathrm{n}=62)$ и КГ (n=19) в течение курса иммунотерапии ритуксимабом

Fig. 5. Dynamics of serum concentrations of antineuronal autoantibodies in patients SG $(n=62)$ and CG ( $n=19)$ during the course of immunotherapy with rituximab 
реакции на уровне 1-2 баллов, тогда как все пациенты с парциальной резистентностью к ритуксимабу, прошедшие все 9 месяцев апробированных иммунотерапевтических вмешательств без полного устранения антинейрональных аутоантител из сыворотки крови, имели высокую выходную балльную оценку на уровне 5 баллов $\left(p<0,05 ; Z<Z_{0,05}\right)$.

Дополнительно был проведен сравнительный анализ эффективности применения ритуксимаба при антинейрональном аутоиммунитете, обусловленном аутоантителами к калиевым каналам нейронов и GADA, поскольку это позволяло сделать значительное количество подобных случаев в ИГ (рис. 6). Сепаратный анализ динамики сывороточных концентраций других аутоантител к нейронам ЦНС, отмечавшихся у детей ИГ, был невозможен из-за малого количества соответствующих наблюдений.

Как показывают результаты рис. 6, ритуксимаб, вероятно, был более эффективен у пациентов с аутоантителами к калиевым каналам нейронов, чем при продукции аутоантител к GADA, хотя есть основания полагать, что эффективность иммунотерапии была достаточно высокой в обоих случаях. Эти результаты согласуются с общепринятыми представлениями о том, что ритуксимаб более эффективен при антинейрональном аутоиммунитете, обусловленном аутоантителами к поверхностным аутоантигенам, чем аутоантителами к внутриклеточным аутоантигенам нейронов, поскольку в последнем случае больший удельный вес в патогенезе болезни имеют клеточные механизмы аутоиммунитета, на которые не действует применяемый препарат моноклональных антител [37].

Следовательно, можно ожидать, что при идентификации серологических признаков антинейронального аутоиммунитета к GADA у детей с РАС, ассоциированными с ГДФЦ, будет более длительный курс иммунотерапии ритуксимабом, чем при выявлении аутоантител к калиевым каналам нейронов. Возможно, для выравнивания ожидаемых сроков иммунотерапии в обоих указанных случаях следует стартово применять более высокие дозы ритуксимаба или сочетать стандартную

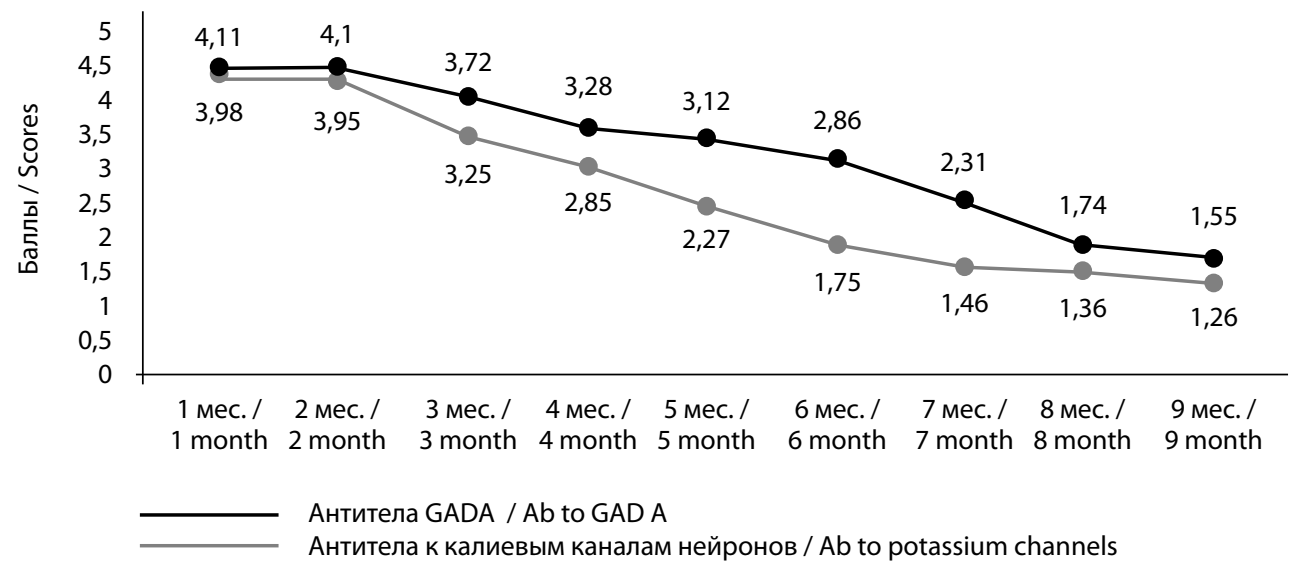

Рис. 6. Динамика сывороточных антинейрональных аутоантител к GADA и калиевым каналов

Fig. 6. Dynamics of serum antineuronal autoantibodies to GADA and potassium channels of neurons in patients $S G(n=62)$ during the course of immunotherapy with rituximab 
иммунотерапию с глюкокортикостероидами именно у пациентов с аутоантителами к GADA в сыворотке крови, что следует проверить в дальнейших исследованиях.

Принципиальным является вопрос, связан ли достигнутый феномен ритуксимаб-индуцированного устранения сывороточных антинейрональных аутоантител с эффектом нейропротекции. Для этого изучили ассоциацию негативизации результатов серологических тестов с нормализацией ранее повышенных сывороточных концентраций биомаркеров церебрального повреждения нейрон-специфической энолазы (NSE) и белка S-100 (табл. 1), релевантность которых ранее продемонстрирована в специально спланированных контролируемых клинических исследованиях у детей с РАС [31, 32].

Как видно из результатов табл. 1, исчезновение сывороточных аутоантител как к GADA, так и к калиевым каналам нейронов было ассоциировано с нормализацией ранее повышенных концентраций обоих исследуемых лабораторных биомаркеров церебрального повреждения, что позволяет предположить нейропротекторный эффект иммунотерапии ритуксимабом у детей ИГ. В подгруппе пациентов с аутоантителами к калиевым каналам нейронов отмечалась выраженная ассоциация динамики серологического показателя и церебрального биомаркера по сравнению с подгруппой лиц с аутоантелами к GADA, что согласуется с результатами анализа динамики сывороточных концентраций обоих видов антинейрональных аутоантител в течение курса иммунотерапии ритуксимабом в ИГ. При этом имела место более тесная ассоциация с NSE по сравнению с белком S-100, что можно объяснить тропностью выявленных антицеребральных аутоантител у детей ИГ. Поскольку отмечались именно антинейрональные аутоантитела, которые поражают прежде всего серое вещество головного мозга, более информативной оказалась именно NSE, характеризующая повреждения именно нейронов, а не белок S-100, сывороточная концентрация которого повышается при повреждении белого вещества полушарий большого мозга [38, 39].

Важно было также исследовать клиническую значимость феномена ритуксимаб-индуцированного исчезновения аутоантител к нейронам ЦНС у детей ИГ, поскольку до сих пор идут дискуссии о роли антинейронального аутоимунитета в патогенезе РАС у детей. Данные динамики балльной оценки психического состояния детей по шкале

\section{Таблица 1}

Результаты изучения ассоциации феномена негативизации результатов серологических тестов и нормализации сывороточных концентраций NSE и белка S-100 (OR; 95\% CI) в ИГ (n=62)

\begin{tabular}{|l|l|l|}
\hline Показатель & Антитела к GADA & Антитела к калиевым каналам нейронов \\
\hline NSE & 17,$875 ; 4,738-67,436$ & 41,$800 ; 7,257-240,778$ \\
\hline S-100 & 9,$750 ; 2,707-35,113$ & 18,$333 ; 3,462-97,083$ \\
\hline
\end{tabular}

Table 1

Results of the study of the association of the phenomenon of negative serological test results and normalization of serum concentrations of NSE and protein S-100 (OR; $95 \% \mathrm{CI})$ in SG $(n=62)$

\begin{tabular}{|l|l|l|}
\hline Index & Ab to GADA & Ab to potassium channels \\
\hline NSE & $17.875 ; 4.738-67.436$ & $41.800 ; 7.257-240.778$ \\
\hline S-100 & $9.750 ; 2.707-35.113$ & $18.333 ; 3.462-97.083$ \\
\hline
\end{tabular}


Эффективность ритуксимаба при расстройствах спектра аутизма, ассоциированных с генетическим дефицитом фолатного цикла, с признаками антинейронального аутоиммунитета

\section{Таблица 2}

Показатели шкалы АВС в баллах у пациентов ИГ (n=62) и КГ (n=19) после завершения курса иммунотерапии ритуксимабом

\begin{tabular}{|l|l|l|l|}
\hline № & Субшкалы & ИГ (n=62) & KГ (n=19) \\
\hline АВC & Возбудимость (irritability) & $6,4 \pm 0,8^{*}$ & $14,1 \pm 1,5$ \\
\hline 1 & Гиперактивность (hyperactivity) & $10,9 \pm 1,4^{*}$ & $22,5 \pm 2,1$ \\
\hline 3 & $\begin{array}{l}\text { Неадекватный глазной контакт } \\
\text { (inadequate еуе сопtact) }\end{array}$ & $4,1 \pm 0,8^{*}$ & $8,6 \pm 1,3$ \\
\hline 4 & $\begin{array}{l}\text { Несоответствующая речь (inapppropriate } \\
\text { speech) }\end{array}$ & $1,6 \pm 0,5^{*}$ & $7,9 \pm 1,5$ \\
\hline Symptom Checklist & & \\
\hline 1 & Сонливость (drowsiness) & $5,7 \pm 0,7^{*}$ & $14,2 \pm 1,4$ \\
\hline 2 & Сниженная активность (decreased activity) & $1,7 \pm 0,4^{*}$ & $5,4 \pm 0,5$ \\
\hline
\end{tabular}

Примечание: * $\mathrm{p}<0,05: \mathrm{Z}<\mathrm{Z}_{0,05}$.

Table 2

Indicators of the ABC scale in scores in patients SG $(n=62)$ and CG $(n=19)$ after completion of the course of immunotherapy with rituximab

\begin{tabular}{|l|l|l|l|}
\hline № & Subscales & SG $(n=62)$ & CG $(n=19)$ \\
\hline ABC & Irritability & $6.4 \pm 0.8^{*}$ & $14.1 \pm 1.5$ \\
\hline 1 & Hyperactivity & $10.9 \pm 1.4^{*}$ & $22.5 \pm 2.1$ \\
\hline 2 & Inadequate eye contact & $4.1 \pm 0.8^{*}$ & $8.6 \pm 1.3$ \\
\hline 3 & Inapppropriate speech & $1.6 \pm 0.5^{*}$ & $7.9 \pm 1.5$ \\
\hline 4 & & $5.7 \pm 0.7^{*}$ & $14.2 \pm 1.4$ \\
\hline Symptom & Checklist & $1.7 \pm 0.4^{*}$ & $5.4 \pm 0.5$ \\
\hline 2 & Drowsiness & \\
\hline
\end{tabular}

Note: ${ }^{*} p<0.05: Z<Z_{0.05}$.

АВС указывают на существенное улучшение со стороны всех исследуемых показателей у детей, получавших иммунотерапию ритуксимабом, по сравнению с пациентами КГ. Имели место снижение выраженности клинических проявлений гиперактивности и гипервозбудимости, улучшение зрительного контакта и поведения, рост общей балльной оценки психического развития ребенка. Эти клинические эффекты развивались и углублялись в течение курса иммунотерапии по мере снижения сывороточных концентраций аутоантител к нейронам ЦНС (табл. 2).

Эти данные дают основание полагать, что аутоиммунитет к нейронам ЦНС может быть важным компонентом патогенеза РАС у детей с ГДФЦ, а устранение серологических проявлений антинейронального аутоиммунитета с помощью ритуксимаба может быть ассоциировано с достоверным улучшением со стороны психического состояния детей. Таким образом, иммунотерапия ритуксимабом, вероятно, модифицирует психическое состояние детей с РАС, ассоциированными с ГДФЦ, равномерно воздействуя на все основные клинические признаки психической болезни. Целесообразно проведение дополнительных контролируемых клинических исследований по апробации ритуксимаба у детей с РАС, ассоциированными с ГДФЦ, с признаками антимозгового аутоиммунитета для уточнения полученных данных. 


\section{- ВЫВОДЫ}

По-видимому, у некоторых пациентов с РАС, ассоциированными с ГДФЦ, имеются клинико-лабораторно-радиологические признаки, характерные для хронического аутоиммунного лимбического энцефалита, что может быть связано с развитием по крайней мере части проявлений нарушения психики в таких случаях. Аутоантитела к GADA и калиевым каналам нейронов, которые ранее были валидированы как лабораторные маркеры аутоиммунных лимбических энцефалитов и не характерны для здоровых людей, встречаются у детей с РАС, ассоциированными с ГДФЦ, наиболее часто по сравнению с другими серологическими маркерами антинейронального аутоиммунитета (87\% случаев). Есть основания полагать, что лечение ритуксимабом приводит к прогрессивному снижению сывороточной концентрации антинейрональных аутоантител у пациентов с РАС, ассоциированными с ГДФЦ, с более выраженным эффектом при продукции аутоантител к калиевым каналам нейронов по сравнению с аутоантителами к GADA с полным устранением всех видов аутоантител из сыворотки крови пациентов после 3-9-месячного курса иммунотерапии, по меньшей мере в 92\% случаев. Феномен ритуксимаб-индуцированного устранения сывороточных антинейрональных аутоантител, вероятно, ассоциирован с эффектом нейропротекции, на что указывает нормализация ранее повышенных сывороточных концентраций лабораторных биомаркеров церебрального повреждения NSE и белка S-100 в сыворотке крови. Наиболее вероятно, что именно достигнутый нейропротекторный эффект вызывает прогрессивное улучшение со стороны основных клинических проявлений РАС у детей с ГДФЦ в течение всего курса иммунотерапии. Полученные данные подтверждают клиническую значимость сывороточных антинейрональных аутоантител у детей с РАС, ассоциированными с ГДФЦ, и свидетельствуют об эффективности применения ритуксимаба с целью нейропротекции путем угнетения антимозгового аутоиммунитета и достижения связанного с этим улучшения психического статуса ребенка в таких случаях. Необходимо проведение дальнейших исследований в этом направлении с большим количеством участников и более совершенным дизайном для уточнения полученных данных.

Конфликт интересов. Автор заявляет об отсутствии конфликта интересов.

Conflict of interests. The author declares no conflict of interests.

\section{- ЛИТЕPATУPA/REFERENCES}

1. Li Y., Qiu S., Shi J. (2020) Association between MTHFR C677T/A1298C and susceptibility to autism spectrum disorders: a meta-analysis. BMC Pediatr, vol. 20, no 1, p. 449

2. Mohammad N.S., Shruti P.S., Bharathi V. (2016) Clinical utility of folate pathway genetic polymorphisms in the diagnosis of autism spectrum disorders. Psychiatr. Genet, vol. 26, no 6, pp. 281-86.

3. Pu D., Shen Y., Wu J. (2013) Association between MTHFR gene polymorphisms and the risk of autism spectrum disorders: a meta-analysis. Autism Res, vol. 6, no 5, pp. 384-392.

4. Rai V. (2016) Association of methylenetetrahydrofolate reductase (MTHFR) gene C677T polymorphism with autism: evidence of genetic susceptibility. Metab. Brain Dis, vol. 31, no 4, pp. 727-35.

5. Sadeghiyeh T., Dastgheib S.A., Mirzaee-Khoramabadi K. (2019) Association of MTHFR 677C >T and 1298A >C polymorphisms with susceptibility to autism: A systematic review and meta-analysis. Asian J Psychiatr, vol. 46, pp. 54-61. 
6. Gupta S. (1999) Treatment of children with autism with intravenous immunoglobulin. J. Child. Neurol, vol. 14, no 3, pp. $203-205$.

7. Wang Z., Ding R., Wang J. (2020) The Association between Vitamin D Status and Autism Spectrum Disorder (ASD): A Systematic Review and Meta-Analysis. Nutrients, vol. 13, no 1, E86.

8. Yektaş Ç., Alpay M., Tufan A.E. (2019) Comparison of serum B12, folate and homocysteine concentrations in children with autism spectrum disorder or attention deficit hyperactivity disorder and healthy controls. Neuropsychiatr. Dis. Treat, vol. 15, pp. 2213-19.

9. Chen L., Shi X.J., Liu H. (2021) Oxidative stress marker aberrations in children with autism spectrum disorder: a systematic review and metaanalysis of 87 studies (N=9109). Transl. Psychiatry, vol. 11, no 1, p. 15.

10. Frustaci A., Neri M., Cesario A. (2012) Oxidative stress-related biomarkers in autism: systematic review and meta-analyses. Free Radic. Biol. Med, vol. 52, no 10, pp. 2128-41.

11. Mead J., Ashwood P. (2015) Evidence supporting an altered immune response in ASD. Immunol. Lett, vol. 163, no 1, pp. 49-55.

12. Noriega D.B., Savelkoul H.F. (2014) Immune dysregulation in autism spectrum disorder. Eur. J. Pediatr, vol. 173, no 1, pp. 33-43.

13. Nicolson G.L., Gan R., Nicolson N.L., Haier J. (2007) Evidence for Mycoplasma ssp., Chlamydia pneunomiae, and human herpes virus-6 coinfections in the blood of patients with autistic spectrum disorders. J. Neurosci Res, vol. 85, no 5, pp. 1143-48.

14. Cabanlit M., Wills S., Goines P. (2007) Brain-specific autoantibodies in the plasma of subjects with autistic spectrum disorder. Ann. N. Y. Acad. Sci, vol. 107, pp. 92-103.

15. Frye R.E., Sequeira J.M., Quadros E.V. (2013) Cerebral folate receptor autoantibodies in autism spectrum disorder. Mol. Psychiatry, vol. 18, no 3, pp. 369-81.

16. Masi A., Quintana D.S., Glozier N. (2015) Cytokine aberrations in autism spectrum disorder: a systematic review and meta-analysis. Mol. Psychiatry, vol. 20 , no 4, pp. $440-46$.

17. Saghazadeh A., Ataeinia B., Keynejad K. (2019) A meta-analysis of pro-inflammatory cytokines in autism spectrum disorders: Effects of age, gender, and latitude. J. Psychiatr. Res, vol. 115, pp. 90-102.

18. Marchezan J., Geyer E., Winkler A. (2018) Immunological Dysfunction in Autism Spectrum Disorder: A Potential Target for Therapy. Neuroimmunomodulation, vol. 25, no 5-6, pp. 300-319.

19. Boris M., Goldblatt A., Edelson S.M., Edelson PA-C. (2006) Improvement in children with autism treated with intravenous gamma globulin. J. Nutr. Environ. Medicine, vol. 15, no 4, pp. 1-8.

20. Bradstreet J., Singh V.K., El-Dahr J. (1999) High dose intravenous immunoglobulin improves symptoms in children with autism. The international symposium on autism. Atnhem., Netherlands.

21. Connery K., Tippett M., Delhey L.M., Rose S. (2018) Intravenous immunoglobulin for the treatment of autoimmune encephalopathy in children with autism. Transl. Psychiatry, vol. 8, no 1, p. 148.

22. DelGiudice-Asch G., Simon L., Schmeidler J. (1999) Brief report: a pilot open clinical trial of intravenous immunoglobulin in childhood autism. J. Autism Dev. Disord, vol. 29, no 2, pp. 157-160.

23. Gupta S. (1999) Treatment of children with autism with intravenous immunoglobulin. J. Child. Neurol, vol. 14, no 3, pp. $203-205$.

24. Gupta S., Samra D., Agrawal S. (2010) Adaptive and Innate Immune Responses in Autism: Rationale for Therapeutic Use of Intravenous Immunoglobulin. J. Clin. Immunol, vol. 30, no 1, pp. 90-96.

25. Maltsev D. (2019) Efficiency of a high dose of intravenous immunoglobulin in children with autistic spectrum disorders associated with genetic deficiency of folate cycle enzymes, Journal of global pharma technology, vol. 11, no 05, pp. 597-609.

26. Melamed I.R., Heffron M., Testori A., Lipe K. (2018) A pilot study of high-dose intravenous immunoglobulin $5 \%$ for autism: Impact on autism spectrum and markers of neuroinflammation. Autism Res, vol. 11, no 3, pp. 421-33.

27. Niederhofer H., Staffen W., Mair A. (2003) Immunoglobulins as an alternative strategy of psychopharmacological treatment of children with autistic disorder. Neuropsychopharmacology, vol. 28, no 5, pp. 1014-15.

28. Plioplys A.V. (1998) Intravenous immunoglobulin treatment of children with autism. J. Child. Neurol, vol. 13, no 2, pp. 79-82.

29. Mal'cev D., Natrus L. (2020) Effektivnost' infliksimaba pri rasstrojstvah spektra autizma, associirovannyh s geneticheskim deficitom folatnogo cikla [Efficacy of Infliximab in Autism Disorders Associated with a Genetic Folate Cycle Deficiency]. Psihiatriya, psihoterapiya i klinicheskaya psihologiya, vol. 11, no 3, pp. 583-94.

30. Nepal G., Shing K.Y., Yadav J.K. (2020) Efficacy and safety of rituximab in autoimmune encephalitis: A meta-analysis. Acta Neurol. Scand, vol. 142, no 5, pp. 449-59.

31. Lv M.N., Zhang H., Shu Y. (2016) The neonatal levels of TSB, NSE and CK-BB in autism spectrum disorder from Southern China. Transl. Neurosci, vol. 7, no 1, pp. 6-11.

32. Zheng Z., Zheng P., Zou X. (2020) Peripheral Blood S100B Levels in Autism Spectrum Disorder: A Systematic Review and Meta-Analysis. J. Autism. Dev. Disord. Online ahead of print.

Подана/Submitted: 08.06.2021

Принята/Accepted: 18.08 .2021

Контакты/Contacts: dmaltsev@ukr.net 